\title{
PREVENTIVNA ZAŠTITA MISNOG RUHA IZ FRANJEVAČKOG SAMOSTANA U POŽEGI
}

\begin{abstract}
Sažetak
Zbirka crkvenog tekstila iz Franjevačkog samostana u Požegi sadrži 164 tekstilna predmeta: 28 misnica, 12 plašteva, 1 kukuljicu, 21 dalmatiku, 47 štola, 28 manipula, 13 veluma, 9 bursi, 3 pale, 1 mitru i 1 fragment tkanine. Predmeti su izrađeni uglavnom od svilenih, pamučnih i lanenih tkanina koje su dekorirane raznobojnim nitima svile, metalnim nitima i lamelama. Vez na pojedinim tkaninama izveden je u tehnikama pisanca i plosnog veza, križnim bodom i slikanjem iglom, a neke tkanine ukrašene su strojno tehnikom tambura. Predmeti su bili uglavnom dobro očuvani, ali prašnjavi s mjestimice vidljivim mehaničkim oštećenjima i oksidativnim promjenama na tkanim ukrasnim trakama. Dvije najstarije misnice datirane u 1646. i 1728. godinu bile su pohranjene s ostalim tekstilnim predmetima u ormarima s drvenim ladicama. Tekstilni predmeti preuzeti su iz Franjevačkog samostana u Požegi i transportirani u Restauratorski odjel Ludbreg, gdje je najprije provedena dezinsekcija u modificiranoj atmosferi s plinovitim dušikom. Izrađena je grafička i fotografska dokumentacija za svaki predmet, a potom je na svim predmetima proveden suhi postupak čišćenja. Crkveni tekstil numeriran je i sortiran u trideset dva kompleta, dok su ostali predmeti sortirani prema vrsti predmeta. U privremenim spremnicima transportirani su u Franjevački samostan u Požegi, gdje su svi predmeti pohranjeni u tri metalna ladičara.
\end{abstract}

Ključne riječi: crkveni tekstil; zaštita; dezinsekcija.

\section{Uvod}

Povijesni tekstilni predmeti dio su pokretne kulturne baštine Republike Hrvatske. Najčešće se radi o crkvenom i svjetovnom tekstilu koji nalazimo u zaštićenim zbirkama uz druge uporabne i dekorativne tekstilne predmete koji se čuvaju u crkvama i muzejima.

Zbog osjetljivosti takvih predmeta na različite fizikalno-kemijske procese kojima su izloženi, a kako već svojim nastankom, uporabom i starenjem započinju proces promjene i degradacije, javlja se potreba za neodgodivim djelovanjem primjenom konzervatorsko-restauratorskih metoda. 
Prije svega radi se o preventivnom konzerviranju, odnosno preventivnoj zaštiti koja ima za cilj sprečavanje daljnje štete i usporavanje procesa propadanja. Riječ je o postupcima i metodama kojima se ne zadire u strukturu i materiju tekstilnog predmeta. U tu svrhu provode se istraživanja i primjenjuju se radovi kojima će se poboljšati sigurnost predmeta iz zbirki poboljšanjem okolišnih uvjeta u kojima se tekstilni predmeti nalaze. Najveći utjecaj na stanje predmeta ima temperatura i relativna vlažnost zraka te količina prirodne i umjetne rasvjete, odnosno oscilacije $u$ njihovim vrijednostima. Porast temperature može utjecati na termokemijske procese u molekulama organskog materijala i dovesti do degradacije. Povišene temperature sinergijski ubrzavaju fotokemijske reakcije, utječu na promjenu obojenja tekstilnih tkanina te utječu na vrijednosti relativne vlažnosti zraka. Neodgovarajuća vrijednost relativne vlažnosti zraka omogućuje i potpomaže biološku aktivnost na tekstilnom materijalu. Također može ubrzati određene kemijske reakcije, a najčešće izaziva fizikalne promjene dimenzija materijala. Kada je relativna vlažnost učestalo veća od $70 \%$, na većini organskih materijala pojavljuje se plijesan, a njezin razvoj dodatno potpomažu toplina, mrak i ustajali zrak (Vokić, 2007.). Ultraljubičasto zračenje i vidljiva svjetlost izazivaju diskoloraciju na predmetima, utječu na promjene $u$ polimernom lancu i pucanje veza u makromolekulama, pri čemu se smanjuje čvrstoća tekstilnih vlakana (Čunko; Andrassy, 2005). Vrlo je važan način na koji se rukuje predmetima, monitoring prostora radi kontrole štetnika i izrada plana za djelovanje u slučaju raznih nepogoda.

Programom preventivne zaštite u 2014. godini obuhvaćeni su predmeti iz zbirke crkvenog tekstila iz Franjevačkog samostana u Požegi. U zbirci su sadržana 164 predmeta, i to: 28 misnica, 12 plašteva i 1 kukuljica, 21 dalmatika, 47 stola, 28 manipula, 13 veluma, 9 bursi, 3 pale te 1 fragment tkanine i 1 mitra. Crkveni je tekstil iz te zbirke u bijelom, crvenom, zelenom, ljubičastom i crnom tonu obojenja, ovisno o razdoblju liturgijske godine i vrsti blagdana za koji se koristi. Tekstilni predmeti izrađeni su od jednobojnih i višebojnih tekstilnih tkanina od prirodnih vlakana biljnog i životinjskog podrijetla. Uglavnom su to svilene, pamučne i lanene tkanine $u$ platnenom, atlasnom i kepernom vezu te njihovim izvedenicama. Tkanine su dekorirane broširanjem i lizeriranjem efektnim nitima od prirodnih vlakana, metalnim nitima i lamelama. Ukrasni elementi na tkaninama uglavnom su izvedeni $u$ tehnikama tkanja, apliciranja i vezenja. Vezeni ornamenti na pojedinim su tkaninama izvedeni u tehnikama ravnog, plošnog, križnog i omčastog boda. Crkveni tekstilni predmeti izrađeni su u 19. i 20. stoljeću, a dvije najstarije misnice datirane su u 1646. i 1728. godinu.

Crkveni tekstil iz Franjevačkog samostana više se ne upotrebljava u liturgiji. Svi tekstilni predmeti uglavnom su dobro očuvani, ali su onečišćeni aerosolnom prljavštinom s mjestimice vidljivim mehaničkim oštećenjima i oksidativnim promjenama 
na tkanim ukrasnim trakama. Čuvali su se u posebnoj prostoriji samostana složeni u tri drvena ormara. U drvenim ormarima tekstilni predmeti bili su višeslojno položeni direktno na drvene ploče na izvlačenje te su zatečeni s brojnim pregibima. Takav način pohrane nije bio primjeren s obzirom na to da između tekstilnih predmeta nije bilo zaštitnih slojeva, dijelovi ormara bili su crvotočni, a drvene su ploče pri izvlačenju zapinjale $u$ utorima zbog djelovanja povišene vlage na drvenu konstrukciju (fotografija 1). Radi poboljšanja uvjeta čuvanja, nabavljeni su metalni ladičari. Prije smještaja predmeta u metalne ladičare, radi provedbe preventivne zaštite, crkveni je tekstil iz Franjevačkog samostana dopremljen na Odsjek za tekstil Restauratorskog odjela Ludbreg Hrvatskog restauratorskog zavoda.



Fotografija 1. Stanje prije radova (foto Ada Vrtulek Gerić)

\section{Postupak preventivnog konzerviranja}

Za suzbijanje eventualne zaraze štetnicima, a kao kurativna mjera, najprije je na predmetima provedena dezinsekcija. Tom fizikalnom metodom tretirani su tekstilni predmeti u komori za fumigaciju s modificiranom atmosferom. Anoksija u komori postignuta je kemijski inertnim plinom dušikom. Tekstilni predmeti tretirani su u periodu od deset tjedana. Prednost te metode jest visoka učinkovitost postupka, bez štetnih učinaka za ljude, umjetnine i okoliš, te to što nema rezidua fumiganta na predmetima. Na taj način moguće je suzbiti sve eventualne štetnike osim plijesni, $u$ svim razvojnim fazama infestacije.

Zatim je proveden postupak suhog čišćenja muzejskim usisavačem. Površina predmeta s vanjske i unutrašnje strane očišćena je od prašine i nevezane prljavštine (Soljačić; Pušić, 2005) usisavačem sa sustavom filtriranja od 6 uzastopnih faza i 
„apsolutnim“ HEPA filtrom, čime se postiže 98\%-tna učinkovitost zadržavanja čestica prašine, gljivica i spora promjera 0,3 mikrona. Regulacija jačine usisa i odabir finoće četkica omogućuje čišćenje tekstilnih predmeta na siguran način. Za čišćenje na mjestima oštećenja upotrijebljena je prilikom čišćenja i zaštitna mreža. Također je proveden suhi postupak čišćenja sistemom usisa preko boca ispiralica plina, pri čemu su istaložene zaostale nečistoće (fotografije 2, 3).

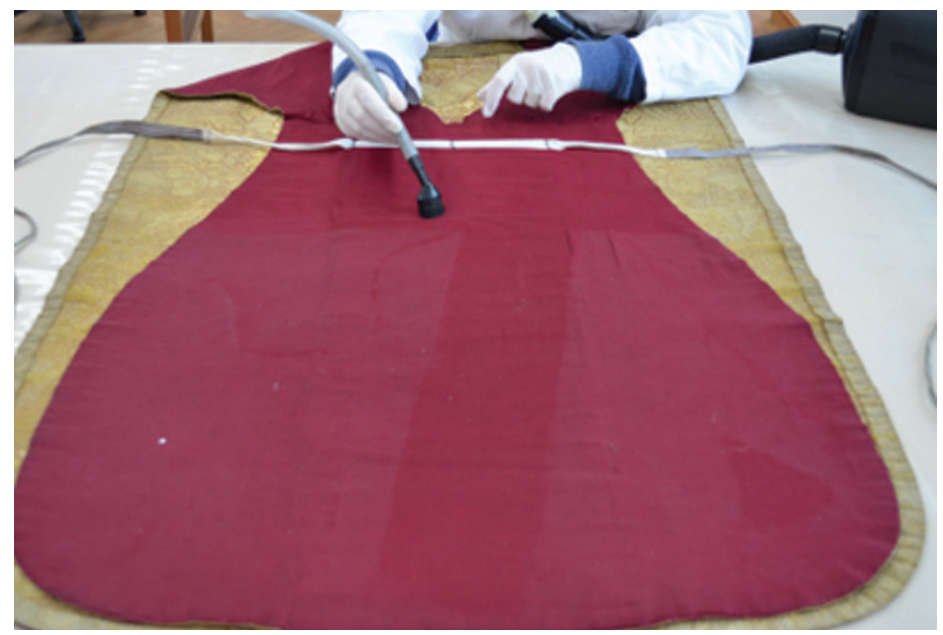

Fotografija 2. Suhi postupak čišćenja (foto Ada Vrtulek Gerić)

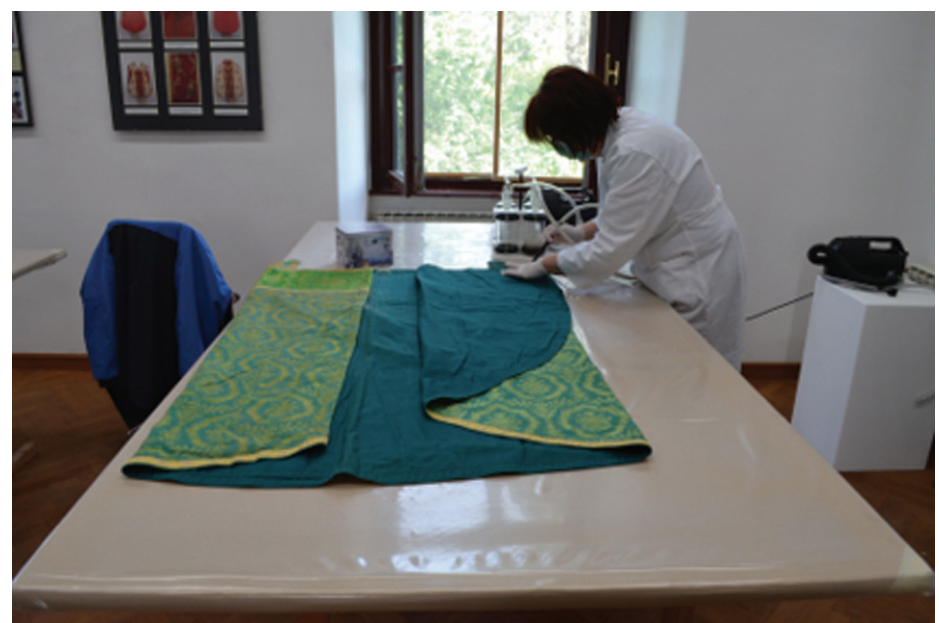

Fotografija 3. Suhi postupak čišćenja (foto Maja Vrtulek) 
Za tekstilne predmete izrađena je fotografska dokumentacija. Fotografirani su totali i detalji tekstilnih predmeta, pri čemu je dokumentirano stanje pojedinog predmeta, efekti u tkanju izvornih tkanina i tkanih ukrasnih traka te detalji ukrasnog veza. Izradom grafičke i pisane dokumentacije dokumentirane su sve dimenzijske i konstrukcijske karakteristike pojedinog predmeta. Utvrđen je temeljni vez tkanina, način izrade ukrasnih motiva i druge specifičnosti.

Svi su predmeti numerirani i označeni (fotografija 4). Oznake su izrađene od beskiselinskog kartona, ispisane su grafitnom olovkom i prišivene su za tekstilni predmet. Nakon postupka čišćenja i izrade dokumentacije predmeti su u privremenim spremnicima transportirani u Franjevački samostan u Požegi u prostoriju koja je prethodno očišćena i u koju su montirani metalni ladičari.
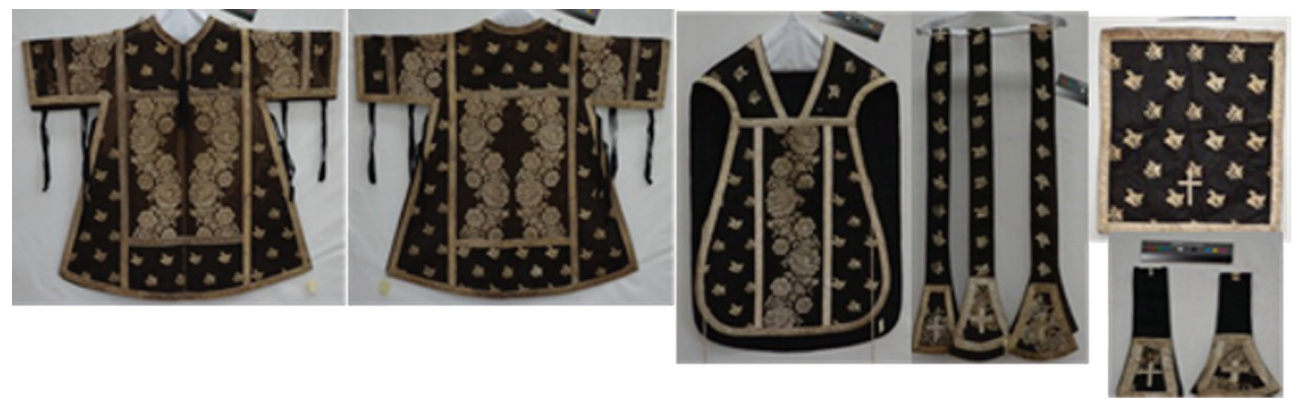

Fotografija 4. Komplet misnog ruha nakon čišćenja (foto Ada Vrtulek Gerić)

Od ukupno 164 predmeta, 113 ih je svrstano u 32 kompleta. Kompleti su složeni $\mathrm{u}$ ladice u vodoravnom položaju, a između predmeta stavljen je sloj od beskiselinskog papira. Veći predmeti, poput dalmatika, presavijeni su s bočnih strana, pri čemu su pregibi osigurani slojevima beskiselinskog papira. Ostali predmeti pohranjeni su pojedinačno, s obzirom na vrstu i namjenu tekstilnog predmeta. U svakoj je ladici završni sloj od netkane tekstilije Avosa kako bi se predmeti dodatno zaštitili. Tekstilni predmeti pohranjeni na taj način mogu se sigurno čuvati od utjecaja prašine, svjetla i vlage (fotografije 5, 6). 


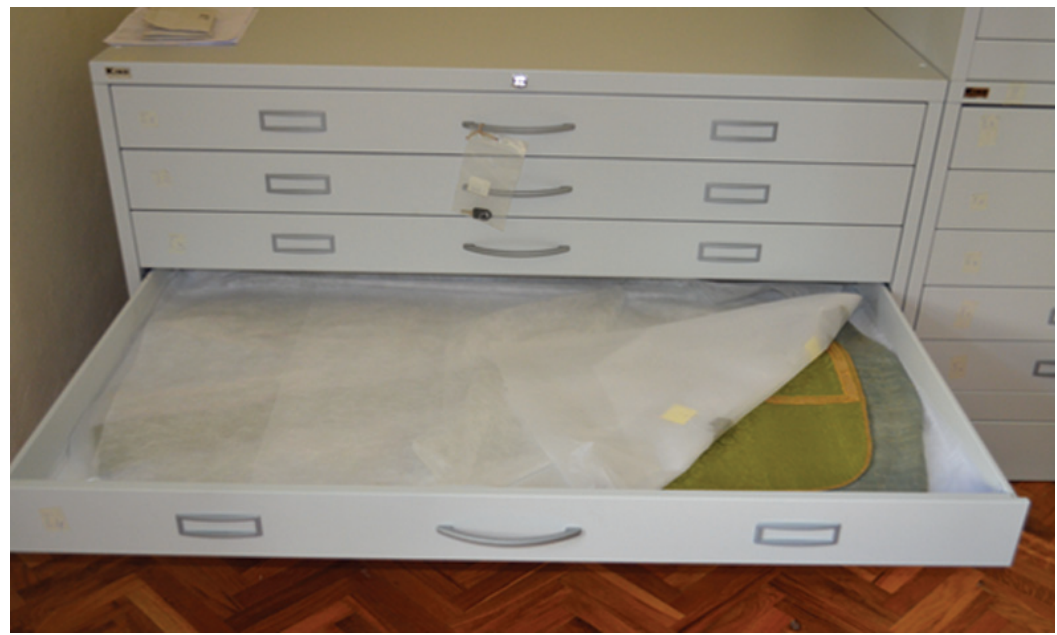

Fotografija 5. Smještaj ruha u ladičare nakon radova (foto Ada Vrtulek Gerić)

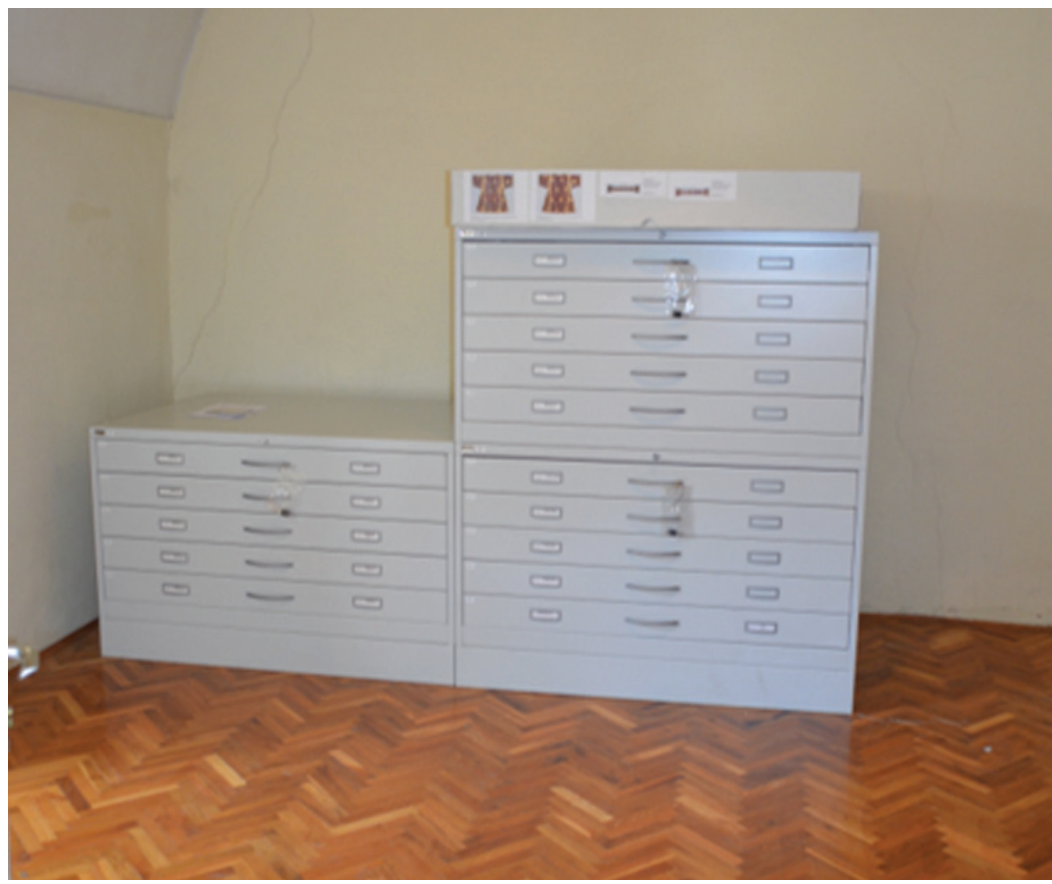

Fotografija 6. Stanje nakon radova (foto Ada Vrtulek Gerić) 


\section{Preporuke za pohranu i čuvanje umjetnina od tekstila}

Umjetnine od tekstila uvijek treba čuvati izdvojeno od predmeta načinjenih od drugih materijala. Isto tako restaurirane tekstilne predmete treba čuvati odvojeno od nerestauriranih predmeta. Za tekstilne predmete $\mathrm{u}$ čuvaonici optimalna vrijednost mikroklimatskih uvjeta jest: $18{ }^{\circ} \mathrm{C}$ temperature i relativna vlažnost zraka (RV) od oko 45 - 50\%. Prostor za pohranu tekstila uvijek mora biti čist od nametnika, stoga je potreban periodični pregled prostora i umjetnina koje se u njemu nalaze. U prostoru ne smije biti predmeta od gume, kao ni hrastovo, kestenovo i brezovo drvo, jer luče kiseline koje štete umjetninama. Manje je štetno borovo, jelovo, smrekovo i brijestovo drvo. Prostor za pohranu mora biti organiziran tako da je do svakog predmeta jednostavno doći, skinuti ga s police ili izvaditi iz ladice. Predmeti ne smiju biti na podu ni položeni direktno uza zid. Svi tekstilni predmeti moraju biti obilježeni na primjeren način. Za čuvanje umjetnina od tekstila idealan je vodoravni položaj (HRZ, 2014).

\section{Literatura}

Čunko, Ružica, Andrassy, Maja (2005), Vlakna, Čakovec: Biblioteka znanstveno popularna djela, knjiga 51.

Hrvatski restauratorski zavod (2014), Izvješće o provedenoj preventivnoj zaštiti na misnom ruhu iz Franjevačkog samostana u Požegi, Restauratorski centar Ludbreg, Odsjek za tekstil.

Soljačić, Ivo, Pušić, Tanja (2005), Njega tekstila, Varaždin: Tekstilno-tehnološki fakultet Sveučilišta u Zagrebu.

Vokić, Denis (2007), Preventivno konzerviranje slika, polikromiranog drva i mješovitih zbirki, Zagreb: K-R CENTAR, Hrvatsko restauratorsko društvo. 


\section{Preventive Protection of Liturgical Vestments from the Franciscan Monastery in Požega}

Summary

The collection of church textiles from the Franciscan monastery in Požega includes 164 textile items: 28 chasubles, 12 copes, one hood, 21 dalmatics, 47 stoles, 28 maniples, 13 humeral veils, 9 burses, 3 chalice veils, one mitre, and one fabric fragment. The items have mainly been made of silk, cotton and linen fabrics decorated with multi-coloured silk and metal threads, and lamellas. The embroidery on several fabrics has been made using flat stitching, cross stitching and needle painting embroidery techniques, and some fabrics have been decorated with machine tambour embroidery. The most of the items were well-preserved, but dusty, and with some visible mechanical damage and oxidation changes on the woven decorative ribbons. The two oldest liturgical vestments, dated 1646 and 1728, were stored with other textile items in wardrobes with wooden drawers. Textile items had been taken over from the Franciscan monastery in Požega and transported to the Ludbreg Conservation Department, where they were first disinfected in a modified atmosphere with nitrogen gas. Documentation including drawings and photographs was made for each item, and the dry cleaning procedure was subsequently carried out on all items. Church textiles were numbered and sorted into thirty-two sets, while other objects were sorted according to type. They were transported in temporary containers to the Franciscan monastery in Požega, where all items were stored in three metal cabinets with drawers.

Keywords: church textiles; protection; disinfection.

Ada Vrtulek Gerić, mag. ing. techn. text.

Hrvatski restauratorski zavod

Restauratorski odjel Ludbreg

Trg Sv. Trojstva 15, 42230 Ludbreg

avgeric@hrz.hr 